\title{
LXXI. Lead and the end product of thorium. (Part II.)
}

\author{
Arthur Holmes A.R.C.S. B.Sc. F.G.S. \& Robert W. Lawson M.Sc.
}

To cite this article: Arthur Holmes A.R.C.S. B.Sc. F.G.S. \& Robert W. Lawson M.Sc. (1915) LXXI. Lead and the end product of thorium. (Part II.), Philosophical Magazine Series 6, 29:173, 673-688, DOI: $10.1080 / 14786440508635349$

To link to this article: http://dx.doi.org/10.1080/14786440508635349

曲 Published online: 08 Apr 2009.

Submit your article to this journal $₫$

Џ Article views: 4

Q View related articles $₫$

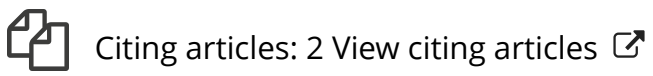


LXXI. Lead and the End Product of Thorium. (Part II.)* $B y$ Arthur Holmes, A.R.C.S., B.Sc., F.G.S., Imperial College, London, and Robert W. Lawson, M.Sc., Radium Institute, Vienna †.

Contents.

§9. Constant of Disintegration of 'Thorium E.

$\S$ 10. Bismuth as a Possible End Product of the Thorium Series.

§ 11. Further Evidence from Atomic Weight Estimations.

$\S 12$. Remarks on the Selection of Material for Atomic Weight Determinations.

§ 13. The Possible End Product of the Actinium Series.

$\S 14$. Conclusions.

\section{§ 9. Constant of Disistegration of Thoriom E.}

$7 \mathrm{HE}$ results we have so far obtained show indirectly 1 that thorium $\mathbf{E}$ is an unstable element, even though the radiation from it has not hitherto been detected. In order to obtain information as to its half-life period we must, then, resort to some method other than those usually used. The present section gives a more complete treatment of a method outlined recently by one of the authors $\ddagger$. Before passing on to this, however, the suggestion made recently by Fajans in this connexion must be considered $\S$. Using the results of an analysis by Boltwood \| of a thorium mineral poor in uranium (thorite), and assuming that all the lead estimated had its origin in thorium, Fajans gave 2.10 years as the maximum possible value of the half-period of thorium $\mathrm{E}$. Absence of knowledge regarding the age of the mineral referred to, renders it difficult if not impossible to determine by how much this value is too great; and in the case of another thorite analysis (by Holmes, loc. cit. 1911), also used by Fajans, where the age is known, it is certain that not more than 12 per cent. of the total lead found can be due to thorium. Using this fact, it can be readily shown that the Th $\mathrm{E} / \mathrm{Th}$ ratio is $8.10^{-5}$, from which the half-period of thorium $\mathrm{E}$ is found to be about $1 \cdot 2.10^{6}$ years. The thorium content of this mineral has been given in Table I. No. 3 (Part I.).

Since thorium $E$ is unstable, it is clear that definite and reliable results for the half-period of this element can only be obtained from analyses of minerals rich in thorium. A

* Part I. of this paper was published in this Magazine, vol. xxviii. pp. 823-840 (Dec. 1914).

+ Communicated by the Authors.

† Lawson, 'Nature,'July 9, 1914, p. 479.

$\S$ Fajans, Heidelberger Akad. Ber., Abh. xi. p. 12 (1914).

Il Boltwood, Am. Journ. Sci. xxiii. p. 88 (1907).

Phil. Mag. S. 6. Vol. 29. No. 173. May 1915. 
fortuitous choice of analyses would be useless for our purpose. The effect of thorium lead must be sufficiently predominant to exert a marked influence in spite of the unavoidable presence of uranium lead. Moreover, it cannot be lightly assumed that in all the minerals given in the above mentioned table, the amount of original lead is the same; and in the event of thorium lead being of relatively short life, it is clear that negligence of this inequality would lead to indefinite or even conflicting conclusions regarding the halt-period of thorium E.

Careful consideration of the analyses made it clear that the only results which could be used with confidence were those of Nos. $3,6,7$, and 12 . The instability of thorium lead, and the large percentage of uranium in mineral No. 12, makes it certain that the effect of thorium $\mathrm{E}$ in affecting the $\mathrm{Pb} / \mathrm{U}$ ritio of this mineral must be very small and, practically speaking, negligible. The value $(0.041)$ for this mineral can thus be taken with great probakility as representative of Devonian minerals. Also, since these four minerals are similar in type, comparable in composition, and from the same locality, it is possible that their contents of original lead are not very different. Vogt* has given $0.000 x$ gram as the average amount of lead in 100 grams of rock. If we assume this value, and give $x$ the value 5 , the corrected $\mathrm{Pb} / \mathrm{U}$ ratios for those minerals poor in thorium show a better agreement than previously. Complete agreement is not to be expected from what has already been said, but the magnitude of this value is evidently of the right order. The value 0.0005 gram will thus be taken as the amount of original lead in 100 grms. of the minerals used for the calculation of the half-period of thorium $E$ by the first two of the following three methods to be described.

The total amount of experimentally found lead is evidently equal to the sum of the following three constituents:(a) Original lead; (b) Uranium lead; (c) Thorium lead. This statement can obviously be expressed in the following form-

$$
\mathrm{Pb}_{t}=\mathrm{Pb}_{o}+k . \mathrm{U}_{t}+m \cdot \mathrm{Th}_{t}
$$

where $\mathrm{Pb}_{t}, \mathrm{U}_{t}$, and $\mathrm{Tb}_{t}$ are the present percentage contents of the minerals in lead, uranium, and thorium respectively. $\mathrm{Pb}_{o}$ is the quantity of original lead present per 100 grams of the mineral ; $k$ is the amount (constant) of uranium lead associated with one gram of uranium in these Devonian minerals; and $m$ is the equilibrium amount of thorium lead associated with one gram of thorium.

(a) In the first method for the determination of the value

* Vogt, Zeit. fiir prakt. Geol. 1898; Holmes, loc. cit. p. 253. 
of $m$, the amount of original lead is assumed as above, and the values of $k$ and $m$ are obtained by solution of two equations obtained as follows. The results of any two of the four analyses Nos. 3, 6, 7, 12 are substituted in the above equation, and the two equations obtained by different combinations of the analyses give on solution the required values of $k$ and $m$. In the following table is given the series of results so obtained:-

TABLE VI. $a$.

\begin{tabular}{|c|c|c|}
\hline $\begin{array}{c}\text { Combination of } \\
\text { Analyses. }\end{array}$ & Value of $k$. & Value of $m$. \\
\hline Nos. $3: 6$ & 0.043 & $5.10^{-5}$ \\
$" 3: 7$ & 0.044 & $4.10^{-5}$ \\
$" 3: 12$ & 0.042 & $7.10^{-5}$ \\
$" 6: 7$ & 0.045 & $1.10^{-5}$ \\
$" 6: 12$ & 0.042 & $8.10^{-5}$ \\
$" 7: 12$ & 0.042 & 8.10 \\
\hline
\end{tabular}

Mean $=6.10^{-5}$

The value obtained from $6: 7$ is undoubtedly too low, and is dne to these two analyses being almost alike.

(b) In the second method we assume $\mathrm{Pb}_{o}=0.0005$, and the value of $k$ to be 0.042 for Devonian minerals, and find the value of $m$ from each of the four analyses Nos. 3, 6, 7, and 12. Before passing on, there is one point to be mentioned in connexion with the value of $k$ above stated. The $\mathrm{Pb}_{t} / \mathrm{U}_{m}$ ratio for No. 12 expressed in terms of the timeaverage value of uranium is $0 \cdot 041$. In this discussion the actual amount of uranium present is being used in the calculations, and hence we must use the ratio between the present lead and uranium contents of the minerals $\mathrm{Pb} / \mathrm{U}$. For mineral No. 12 this is equal to 0.042 . As in the previous case, we require the equation $\mathrm{Pb}_{t}=\mathrm{Pb}_{o}+k \cdot \mathrm{U}_{t}+m$. Th $h_{t}$ for the purpose of calculating $m$, which is the only unknown present. The following table gives the results obtained by this method:-

TaBLe VI. $b$.

\begin{tabular}{|c|c|c|c|}
\hline No. of Analysis... & 3. & 6. & 7. \\
\hline Value of $m \ldots \ldots \ldots . .$. & $7.10^{-5}$ & $10 \cdot 10^{-5}$ & $9.10^{-5}$ \\
\hline
\end{tabular}

$\mathrm{Mean}=8 \cdot 7 \cdot 10^{-5}$ 
There is as good an agreement between this mean and that found by the previous method, as was to be expected from the value of the lead-uranium ratio there found.

(c) The value of $m$ can also be calculated from the four analyses already used, and without any assumption as to the distribution of lead. The unknowns in the expression $\mathrm{Pb}_{t}=\mathrm{Pb}_{o}+k . \mathrm{U}_{t}+m . \mathrm{Th}_{t}$ are clearly $\mathrm{Pb}_{o}, k$, and $m$. By insertion of the results of three of the chosen analyses, three equations are obtained which can be solved for the unknown terms. From the four sets of three equations obtained by use of the analyses $3,6,7,12$, the values of $m$ given in the following table were obtained. The mean value of $m=7.10^{-5}$ here obtained is practically tho mean of those obtained by the two preceding methods, and corresponds to a half-period for thorium $\mathrm{E}$ of $7 \cdot 10^{-5} \times 1 \cdot 5 \cdot 10^{-10}=1 \cdot 05.10^{6}$ years. It is interesting to note that the present method is quite independent of the stability or instability of thorium E. Moreover, since the lead producing power of thorium is only 0.4 that of uranium, it follows that, were thorium $\mathrm{E}$ a stable isotope of lead the value of $m$ would be $0.4 \times 0.042=0.017$, instead of $7 \cdot 10^{-5}$ as found $(0.042$ being the uncorrected lead-uranium ratio for minerals of Devonian age). The wide difference between these two values of $m$ leaves little doubt that thorium $\mathrm{E}$ is relatively unstable. With the object of fixing the value of the half-period of thorium $\mathbf{E}$ more definitely, it is the intention of the authors to examine other suitable minerals of different ages, and to apply to these the same method for the evaluation of the half-period. That the results for the unknowns given in Table VI. $c$ differ from

TABLE VI. $c$.

\begin{tabular}{|c|c|c|c|}
\hline $\begin{array}{c}\text { Combination } \\
\text { of Analyses. }\end{array}$ & Value of $\mathrm{Pb}_{o .}$ & Value of $k$. & Value of $m$. \\
\cline { 1 - 2 } Nos. 3,6,7 & 0.0010 & 0.044 & $2.10^{-5}$ \\
$3,3,7,12$ & 0.0000 & 0.042 & $11 \cdot 4.10^{-5}$ \\
$\Rightarrow 3,6,12$ & 0.0001 & 0.042 & $10.10^{-5}$ \\
$" 6,7,12$ & 0.0026 & 0.042 & $5 \cdot 10^{-5}$ \\
\hline
\end{tabular}

Mean $=7 \cdot 1 \cdot 10^{-5}$

the mean more than in the other cases is only to be expected, since any slight error in the values of the substitutes will most probably be magnified during the process of solution 
of the equations. Our previous assumption regarding the magnitude of $k$ is confirmed. The mean value of $\mathrm{Pb}_{o}=0 \cdot 0009$ is not far removed from that assumed in the first two methods. The result 0.0026 obtained from Nos. $6,7,12$ is certainly too high, the reason most likely being that the analyses 6 and 7 are practically the same.

\section{$\S 10$. Bismuth as a Possible End Product of the Thorium Series.}

The results obtained in the present section have an important significance in relation to another possible end product of thorium. Were thorium $\mathrm{E}$, with a half-period of about $10^{6}$ years, to emit a rays, these should, according to the Geiger-Nuttall law, have a range of about $3 \mathrm{~cm}$. This fact renders it highly improbable that we have here to do with an $\alpha$-ray product, because $\alpha$ rays with the above range would hardly have escaped detection. This would appear to exclude the possibility of the end product being an isotope of mercury in Group II. $b$ of the Periodic Classification. It seems more likely that the disintegration of thorium $\mathrm{E}$ is accompanied by the loss of a $\beta$ ray, which would bring the resulting product into the position of bismuth in Group V.b. In such a case, we are again faced with the task of deciding whether what we may by analogy call thorium-bismuth is a stable or an unstable product. Here again the method used in the present section might be applied. A systematic examination of thorium minerals for bismuth and thorium would be necessary. If the end product of thorium is a stable bismuth isotope, the ratio $\mathrm{Bi} / \mathrm{Th}$ for minerals of the same age should be constant, whereas for minerals of different ages it should vary in a similar manner to that found in the case of the $\mathrm{Pb} / \mathrm{U}$ ratio. On the other hand, if the Group V. $b$ product of thorium is unstable, the suggested analyses would serve to determine its disintegration constant. The following expression would be used in this connexion- $-\mathrm{Bi}_{t}=\mathrm{Bi}_{o}+n . \mathrm{Th}_{t}$. Insertion of the results of two suitable analyses would result in two equations from which the amount of original bismuth $\left(\mathrm{Bi}_{0}\right)$ and the equilibrium constant $(n)$ between thoriumbismuth (thorium F) and thorium could be found. From the value of $n$ so obtained, the half-period of thorium $\mathrm{F}$ could be calculated, and evidence adduced as to whether the succeeding change takes place with loss of an $\alpha$ ray or of a $\beta$ ray. In the former case, the succeeding product would be an isotope of thallium with atomic weight $20.4 \cdot 4$ (Group III.b), and in the latter an isotope of polonium (Group VI. $b$ ). 
Hofmann * has given the results of his analyses of two samples of Bröggerite, from which the following percentage constituents have been calculated. It is clear that if the end

TABLE VII.

\begin{tabular}{|c|c|c|c|c|c|c|c|c|}
\hline \multirow{2}{*}{ Sample. } & \multirow{2}{*}{ U. } & \multirow{2}{*}{$\mathrm{Pb}$. } & \multirow{2}{*}{ Th. } & \multirow{2}{*}{ Bi. } & \multirow{2}{*}{$\mathrm{U}_{m .}$} & \multirow{2}{*}{$\mathbf{T h}_{m}$} & \multicolumn{2}{|c|}{$\begin{array}{c}\text { Age of mineral in millions } \\
\text { of years, }\end{array}$} \\
\hline & & & & & & & $\begin{array}{c}\text { from } \mathrm{Pb} / \mathrm{U}_{m} \\
\text { ratio }\end{array}$ & $\begin{array}{c}\text { from } \mathrm{Bi} / \mathrm{Th}_{m} \\
\text { ratio. }\end{array}$ \\
\hline I..... & $67 \cdot 40$ & $8 \cdot 61$ & $4 \cdot 10$ & $0 \cdot 30$ & $72 \cdot 35$ & $4 \cdot 27$ & 1000 & 1490 \\
\hline II....... & $67 \cdot 08$ & $8 \cdot 49$ & $4 \cdot 63$ & 0.33 & 71.96 & 4.82 & 990 & 1440 \\
\hline
\end{tabular}

1 The lead ratios agree with those of the ninerals given in Table II. Part I. p. 835, Moss district, Norway, Age pre-Jatulian.

product of the thorium series is a stable isotope of bismuth $\dagger$, we may use the $\mathrm{Bi} / \mathrm{Th}_{m}$ ratio to determine the age of the mineral. Moreover, the age as calculated in this manner should agree with that as found from the $\mathrm{Pb} / \mathrm{U}_{m} \ddagger$ ratio. The two expressions for the age of the mineral will be respectively $\mathrm{Bi}_{t} / \mathrm{Th}_{m} \times 2 \cdot 09.10^{10}$ years, and $\mathrm{Pb}_{t} / \mathrm{U}_{m} \times 8.58 .10^{9}$ years. $T^{m}$ and $U_{m}$ are the respective time-average values of the thorium and the uranium contents of the mineral, and the ages as found in the case of the mineral under consideration are given in the last two columns of Table VII. In consideration of the relatively small percentages of thorium and bismuth present, and the difficulty of their estimation, it might be thought that the agreement between the ages $v$ ere sufficiently satisfactory to favour the view that thoriumbismuth ("thorium F") might be a stable product.

Opposed to this view, however, is the fact that in the collection of analyses of thorite and allied minerals cited by Hintz in his 'Mineralogie,' vol. i. p. 1675, there is not a single determination of bismuth. Moreover, the Devonian minerals already examined by us have been tested for bismuth with negative results. Hillebrand (Bull. 220, p. 111, U.S.G.S., 1903) gives two analyses of uraninite which

* Hofmann, Ber. d. d. Chem. Ges. xxxiv. p. 914 (1901).

$\dagger$ The part played by original bismuth in such minerals is almost certainly quite negligible. For instance. Vogt (loc. cit.) suggests $0.00000 x$ grm. as the average amount of bismuth in 100 grams of rock (cf. Holmes, loc. cit. 1911, p. 253).

I If actinium lead is unstable, the results obtained for the age of a mineral from the $\mathrm{Pb} / \mathrm{U}$ ratio will be rather low, and if the end product of actinium is bismuth, the age obtained from the $\mathrm{Bi} / \mathrm{Th}$ ratio will be siightly high. 
include determinations of bisnuth, but the latter is clearly independent of the thorium present in each case. More recently Soddy* has examined Ceylon thorite for bismuth and has failed to find an appreciable amount. The evidence is thus fatal to the view that an isotope of bismuth might be the end product of the thorium series.

\section{§ 11. Further Evidence from Atomid Weight Estimations.}

An initial objection to the view that the end product of the uranium family is lead, was that the theoretical atomic weight of the end product radium $G$ did not agree with the atomic weight of lead (207.1) as closely as could be desired. The recent disccvery of isotopic series of elements has demonstrated that chemical identity does not necessarily imply equivalence of atomic weight, and the objection has now lost its original force. Radium $G$ ought to have an atomic weight of 206.2 , calculated from the atomic weight of uranium $(238 \cdot 2)+$, or 206.0 if calculated from the atomic weight of radium $(226 \cdot 0) \ddagger$. The difference between these two values is very small when we consider the intrinsic difficulties of the atomic weight determinations; and the results bear excellent testimony to the careful and exact atomic weight determinations of Hönigschmid. Fortunately, a number of determinations of the atomic weight of lead extracted from radioactive minerals is already to band, and the results are very gratifying. Thanks to the energy with which investigators are attacking the problem, the amonnt of evidence of this nature will soon be considerable, so that further conclusions with regard to the lead disintegration products and their stability will be possible. We may now take the theoretical value for the atomic weight of radium $G$ to be $206 \cdot 2$ without appreciable error. Quite recently Hönigschmid and Fräulein St. Horovitz $\$$, Richards and Lembert\|, and Maurice CurieT, have published the results of their experiments in this connexion. Hönigschmid and Frln. St. Horovitz determined the atomic weight of lead

* Nature, vol. xciv. Feb. 4th, 1915, p. 615.

+ Hönigsehmid, Wien. Anz. 22nd January, 1914.

† Hönigschmid, Wien. Sitzungsber. exx. p. 1017 (1911); cxxi. p. 1973 (1912); cxxi. p. 2110 (1912).

$\S$ Hönigschmid and St. Horovitz, Wien. Anz. 12th June, 1914; Zeit. fiir Elektroch. xx. p. 319 (1914); C. R. clviii. p. 1797 (1914).

$\|$ Richards and Lembert, Journ. Am. Chem. Soc. vol. xxxvi. 7. p. 1329 (1914); Zeit. für Anorg. Chem. Ixxxviii. p. 429 (1914). See also Fajans, Heid. Akad. Ber. A. Abh. xi. (1914).

of Maurice Curie, Comptes Rendus, clviii. p. 1676 (1914). 
extracted from the Joachimstal (Bohemia) uranium residues, and found the value to be $206 \cdot 736 \pm 0.009$. Richards and Lembert used lead chloride which had been obtained by working up (a) North Carolina uraninite, (b) Joachimstal pitchblende, (c) Colorado carnotite, (d) Cornwall pitchblende, and obtained the following values respectively:$206^{\circ} 4,206 \cdot 57,206 \cdot 59$, and $206 \cdot 86$. The result for $(a)$ is of particular interest, because uraninite is less likely to contain ordinary lead than pitchblende, which is a secondary form of uraninite, and in which ordinary lead may probably be present as impurity. The Joachimstal pitchblende is non-crystalline in structure, and generally contains within its mass veins of other minerals such as galena, and iron and copper pyrites. The uranium residues, obtained from large quantities of the ore, would thus be expected to have a larger content in ordinary lead than selected samples of the pitchblende. This fact is probably the cause of the difference in the atomic weights 206.74 and 206.57 obtained for lead from Joachimstal pitchblende by Hönigschmid and St. Horovitz on the one hand, and by Richards and Lembert on the other. For lead which had been extracted from carefully selected samples of pitchblende free from galena, the former experimenters obtained an atomic weight $206.40^{*}$. For ordinary lead treated by the same method as their other materials, Richards and Lembert obtained the value $207 \cdot 15 \pm 0 \cdot 01$, a figure in close agreement with that given in the International Table. The preliminary results given by M. Curie vary between $206 \cdot 36$ and 206.64 for uranium minerals, whilst for ordinary lead from galena he found the value $207 \cdot 01$.

The results so far obtained clearly show that the lead extracted from uranium minerals (in all the above minerals the quantity of thorium present was very small) has a lower atomic weight than ordinary lead, though the value is bigher than is to be expected from theory. It is quite possible that the discrepancy is due to the presence of ordinary lead in the minerals used, as well as to the presence of actinium lead, of which the atomic weight is considered by Fajans + to be about 207, and by other workers as high as 210 . The presence of one or both of these elements would give an increased atomic weight in the right direction, and so at least in part explain the discrepancy.

Still more recently Hönigschmid and Fräulein St. Horovitz have determined the atomic weight of the lead extracted from (a) Uraninite from Morogoro in German East Africa, and

* Hönigschmid and St. Horovitz, Wien. Anz. 9th July, 1911.

$\dagger$ Fajans, loc. cit. p. 11 (1914).

$\ddagger$ Hönigschmid and St. Horovitz, Wien. Anz. 15th October, 1914. 
(b) Bröggerite from Norway. In the first case they obtained a mean value $206^{\circ} 04$, and in the second case 206.06 . These results would appear to indicate that the presence of ordinary lead as impurity was responsible for the high results obtained with other minerals. The purity of the first mineral $(a)$, and the fact that the second mineral $(b)$ is an old primary unaltered mineral, lend support to the view that these contained a minimum quantity of ordinary lead. The above results show that the lead extracted from the minerals mentioned was practically pure radium $G$.

In the case of thorium lead the evicence is as yet less clear than in the case of uranium lead. If we assume the atomic weight of thorium to be $232 \cdot 4$, then the atomic weight of thorium lead, derived by loss of six helium atoms from thorium, is to be expected to be 208.4*. Soddy and Hyman $\dagger$ have extracted lead from thorite (Ceylon), and in the two preliminary determinations of the atomic weight they have already published, they arrived at the values $208 \cdot 3$ and $208 \cdot 5$. From the known rates of disintegration of uranium and thorium, it can readily be seen from the analysis of the mineral used by the authors cited, that if all the lead were of radioactive origin and thorium lead stable, there should be about thirteen times as much thorium lead present as uranium lead. The theoretical atomic weight to be expected can thus be shown to be $208 \cdot 24$, a result less than that found experimentally. Unfortunately, the evidence in the present case must still be regarded as inconclusive. Richards and Lembert (loc. cit.) have determined the atomic weight of lead separated from thorianite from Ceylon. This material contained 60 per cent. thorium and 20 per cent. uranium, so that if thorium lead be stable, the atomic weight to be expected would be $207 \cdot 40$. The value they actually obtained was 206.82 , suggesting at once the instability of thorium lead. That this result is higher than those found for the other minerals they used, cannot without further evidence be assumed to be due to the presence of a stable thorium lead. The presence of ordinary lead as an original constituent of the mineral, or as an infiltrated secondary product, would very well explain the difference. M. Curie obtained for lead extracted from monazite sand the value 207.08. Here again we are not certain of the rôle played by ordinary lead, and furthermore, this mineral always contains a certain quantity of uranium which would introduce a disturbing factor owing to the presence of radium $G$.

* If the atomic weight of thorium is $232 \cdot 2$, as determined by Hönigschmid (1914), then that of thorium lead would be $208 \cdot 2$.

+ Soddy \& Hymar, Trans. Chem. Soe. cv. 1914, p. 1402. 
From the evidence of atomic weights, we can safely decide that the existence of uranium lead with a lower atomic weight than that of ordinary lead has been proved. Moreover, the most recent results of Hönigschmid show that this has an atomic weight in almost perfect agreement with that theoretically to be expected. In the case of thorium lead the ovidence is much less certain, a fact undoubtedly following from the instability of thorium lead (thorium E).

The following table summarizes the evidence from atomic weights up to the present time.

\section{TABLE VIII.*}

Atomic Weights of Lead from Radioactive Minerals.

\begin{tabular}{|c|c|c|c|c|c|}
\hline \multicolumn{2}{|c|}{$\begin{array}{l}\text { Type of } \\
\text { Lead. }\end{array}$} & \multirow{4}{*}{$\begin{array}{l}\text { Experimenter, } \\
\text { Hönigschmid. } \\
\text { Richards and } \\
\text { Lembert. } \\
\text { M. Curie. }\end{array}$} & Source of material. & $\begin{array}{c}\text { Expected } \\
\text { result.s. }{ }^{1}\end{array}$ & $\begin{array}{l}\text { Actual } \\
\text { results. }\end{array}$ \\
\hline \multicolumn{2}{|c|}{ Ordinary lead. } & & & $207 \cdot 1 \%$ & $207 \cdot 18$ \\
\hline " & $"$ & & $\cdots$ & $207 \cdot 1$ & $201 \cdot 10$ \\
\hline$"$ & " & & Galens. & $207 \cdot 1$ & $207 \cdot 01$ \\
\hline \multicolumn{2}{|c|}{ Uranium lead. } & Hönigschmid and & $\begin{array}{l}\text { Uranium residues } \\
\text { (Joachimstal). }\end{array}$ & & $206 \cdot 74$ \\
\hline$"$ & $"$ & $"$ & $\begin{array}{l}\text { Selected pitchblendo } \\
\text { (Joacbirnstal). }\end{array}$ & $>206 \cdot 2$ & $206 \cdot 40$ \\
\hline$"$ & ". & " & $\begin{array}{l}\text { Uruninite }^{3} \\
\text { (G. E. Africa). }\end{array}$ & $206 \cdot 2$ & $206 \cdot 04$ \\
\hline$"$ & $"$ & Rich & Bröggerite (Norway).4 & $206 \cdot 2$ & $206 \cdot 06$ \\
\hline " & " & $\begin{array}{l}\text { Richards and } \\
\text { Lumbert. }\end{array}$ & U ran & & 20070 \\
\hline$"$ & $"$ & " & $\begin{array}{l}\text { Pitchblende (Joachim- } \\
\text { stal). }\end{array}$ & $>206.2$ & 206.57 \\
\hline$"$ & $"$ & $"$ & Carnutite (Colo & $>206 \cdot 2$ & $\begin{aligned} 206.59 \\
006 \cdot 86\end{aligned}$ \\
\hline ", & $"$ & Maurice Curie. & Pitchblende. & $>206 \cdot 2$ & 206.64 \\
\hline ", & ", & ", & & $>206 \cdot 2$ & $206 \cdot 36$ \\
\hline$"$ & $"$ & $"$ & $\mathbf{Y t}$ & $>$ & $206 \cdot 34$ \\
\hline \multicolumn{2}{|c|}{ Thorium lead ${ }^{5}$. } & Soddy \& Hyman. & Thorite (Ceylon). & $208 \cdot 24$ & $208 \cdot 40$ \\
\hline \multicolumn{2}{|c|}{$\begin{array}{l}\text { Thorium lead }+ \\
\text { Uranium lead. }\end{array}$} & Richards and & Thorianite (Ceylon). & $207 \cdot 40$ & $206 \cdot 83$ \\
\hline$"$ & & Maurice C & Monazite sand. & $?$ & $207 \cdot 08$ \\
\hline
\end{tabular}

- If thorium $\mathrm{E}$ and radium $\mathrm{G}$ are isotopic with lead, and are the respective stable end products of the thorium and uranium families of radio-elements.

2 International atomic weight.

${ }^{3}$ Marckwald, Centralblatt für Min. u. Geol. 1906, p. 761; Chemisches Centralhlatt, 1907, i. p. 369.

- This result would appear to point to the stability of thorium E, if the atomic weights of thorium $\mathrm{l}$ and radium $\mathrm{G}$ are respectively 208.4 and 206.0 . Remembering, however, that in all probability a small quantity of original lead is present in this mineral, it is clear that we must be cautious in drawing conclusions regarding the stability of thorium $E$ from such a result, where the mineral contained only 4 per cent. of thorium. Moreover, the theoretical atomic weight of radium $G, 206$, is likely to be a minimum value.

5 Theoretically 90 per cent. pure. 


\section{§12. Remarks on the Selection of Material for atúmic Weight Determinations.}

If the conclusions reached in the foregoing sections aro correct, we are given a reliable means of guiding the selection of material for the determination of the atomic weights of uranium lead and thorium lead respectively. It is obvious in the former case that the most suitable material is a mineral rich in uranium-such as uraninite-and practically free from thorium. In order to eliminate the effect of original lead in controlling the atomic weight of the extracted lead, it is further clear that the older the mineral, the nearer to the theoretical value $206 \cdot 2$ should be the value of the atomic weight actually found. Since thorium lead is relatively unstable, any effect which the presence of thorium in the mineral might exert will also be eliminated by using geologically old minerals.

The case of thorium lead, however, is not so definite. Here, clearly, rich thorium minerals with as small a percentage of uranium as possible must be used. Further, the best results will be obtained for geologically young minerals, since once the equilibrium amount of thorium lead has been formed, additional time only results in addition of more and more uranium lead, which tends to give a lower value than the theoretical value 208.4 for the atomic weight of thorium lead. The magnitude of this effect is clearly shown by the following example. Suppose we have a mineral with 60 per cent. thorium and 0.4 per cent. uranium, and that we assume it is of post-Cretaceous age, with a lead-uranium ratio of the order 0.01 . On the results of the previous sections it follows that the amount of uranium lead present per 100 grams of the mineral $n$ ill be $0.4 \times 0.01=0.0040$ gram; the amount of thorium lead present will be $60 \times 7 \cdot 10^{-5}=()^{\circ} 0042$ gram; and the amount of original lead $0 \cdot 000 x$ gram. Thus in such a case-and a thorium mineral more free from uranium will be difficult to find - the atomic weight obtained, instead of being equal to the theoretical value $208^{\circ} 4$, would lie at about $207 \cdot 2$. This number is practically equal to the atomic weight of ordinary lead, so that in the present case this element would be without appreciable effect. Thus it would appear to be a difficult matter to obtain a thorium mineral which would give a higher value for the atomic weight of its contained lead than about 207, and the inevitable presence of ordinary lead in minerals prohibits exact calculation of the atomic weight of thorium lead from that found for the lead mixture.

In the case of minerals of greater age than that assumed 
above-and all the minerals hitherto examined are actually very much older - the atomic weights to be expected would be somewhat lower than $207 \cdot 2$. It is interesting to notice that the actual determinations by Richards and Lembert on Ceylon thorianite, and by Curie on monazite, give results in complete harmony with this conclusion. This experimental verification adds still further support to the view that thorium lead is unstable.

\section{§ 13. The Possible End Product of the Actinium Series.}

When uranium is present in a mineral, actinium lead will always be a disturbing factor. Should actinium lead be a stable product, the minimum value of the atomic weight of lead extracted from a thorium-free uranium mineral would be 206.26 if the atomic weight of actinium lead is 207, and 206.50 if the atomic weight of actinium lead is 210 . On the other hand, if actinium lead is of relatively short life, and if about 8 per cent. of uranium is transformed along the actinium series, then the high degree of stability of uranium lead renders it certain that the atomic weight of the latter would be quite inappreciably affected by the presence of nctinium lead, even if this bas an atomic weight of 210 . The recent determinations of the atomic weight of lead from crystalline pitchblende and bröggerite by Hönigschmid, indicate either that the atomic weight of actinium lead is 207 , or that if it is 210 then actinium lead is an unstable product. In the case that it is unstable, evidence with regard to its half-period might be obtained by determining the atomic weight of lead of radioactive origin, obtained on the one hand from geologically young, and on the other hand from geologically old, uranium minerals. It is clear that a higher value should be obtained in the former case than in the latter.

Regarding the end product of actinium there would appear to be three possibilities, each of which we will now consider in turn.

As mentioned in a previous paragraph, the atomic weight determinations of radium $G$ by Hönigschmid indicates that if actinium lead has an atomic weight of 210 , it must be unstable, otherwise instead of obtaining a value 206.04 for lead from Morogoro pitclbblende, the value 206.50 should have been found. It would thus appear certain that the end product of actinium cannot be a stable lead isotope unless this has an atomic weight nearly the same as radium $G$.

The second possibility is that the eud product is an isotope 
of bismuth. There is ground for believing that if actinium lead is unstable, it will disintegrate with the loss of a $\beta$ ray and the resulting formation of a bismuth isotope. As to whether or not this product is stable could readily bo tested. We require the bismuth and uranium contents of a series of uranium minerals. The fact that about 8 per cent. of the uranium in a mineral disintegrates along the actinium series gives a direct means of testing whether the amount of bismuth actually found is of the order of magnitude of that to be expected on the assumption that actinium bismuth is stable. Should actinium bismuth be unstable, then clearly the $\mathrm{Bi} / \mathrm{U}$ ratio should be about the same for all fresh unaltered minerals of whatever age. If, on the other hand, it is a stable product, the $\mathrm{Bi} / \mathrm{U}$ ratio should be constant for minerals of the same age, but it should vary directly with the geological age of the mineral. It is worthy of notice that if actinium bismuth is a stable product, so that appreciable quantities of it can be extracted from uranium minerals, it should be found to have an atomic weight of 210 or 206 , both of which values differ by two units from the atomic weight of ordinary bismuth. This method would appear to be a hopeful one for the question in hand, since a result lying near 210 or 206 would not only point to bismuth as the end product of actinium, but it would also give a means of deciding between 230 and 226 as the atomic weight of actinium. The occurrence of bismuth in radioactive minerals has already been commented upon, and it is to be hoped that in the near future more definite evidence for or against bismuth as the end product of actinium will be forthcoming.

The occurrence of thallium in radioactive minerals has also been noted. For instance, Exner and Haschek* found it to be present spectroscopically in appreciable quantities in pitchblende from Cornwall. The fact that if actinium bismuth is unstable, disintegrating with loss of an $\alpha$ ray, we should have a thallium isotope, renders thallium a possible end product of actinium. The analysis of a series of uranium minerals for uranium and thallium would be necessary to test this suggestion. The method of showing whether this thallium product is stable or unstable is the same as that suggested in the case of bismuth last treated. Further, in this case, the atomic weight of the thallium should be 206 or 202 , instead of the atomic weight 204 of ordinary thallium. It is doubtful whether we are justified in laying very much

* Exner and Haschek, Wien. Sitzungsber. cxxi. p. 1077 (1912). 
stress on the occurrence of thallium in the Cornwall pitchblende, since this is of a very impure nature. Professor Hönigschmid informs us that he has been unable to find appreciable traces of thallium in selected pitchblende from Joachimstal. Now the atomic weights of the lead from pitchblende from these two districts are respectively 206.86 and $206^{\circ} \cdot 40$, results which indicate the greater purity of the Jonchimstal material. It would thus appear that the suggestion regarding thallium as the end product of actinium is higbly improbable.

\section{Conclusions.}

(a) In Part I. of this paper it was shown from the uranium, thorium, and lead contents of four series of radioactive minerals :

(1) That the lead-uranium ratio is remarkably constant in minerals of the same age, and varies sympathetically with the geological age of minerals of different antiquities, so that radium $G$ may be regarded as stable or practically so. It appears impossible that any slight instability that may exist could ever bo definitely detected. The slight deviations in the values of the $\mathrm{Pb} / \mathrm{U}$ ratios are such as can be readily accounted for by the presence of traces of original lead, by the presence of the unstable thorium-lead, and by the possible alterations which the minerals may have suffered since their original crystallization.

(2) That thorium-lead does not tend to accumulate in geological time, $i$. e. thorium $\mathrm{E}$ is an unstable product.

(3) That the $\mathrm{Pb} / \mathrm{U}$ ratios may be used as before and with greater certainty for the determination of geological time and the gradual construction of a complete geological time-scale.

(b) On the assumption that the total lead present in the minerals is made up of three constituents : (a) Uranium lead (radium $G$ ) ; (b) Thorium lead (thorium E) ; and (c) Original lead, it has been shown how the results obtained can be applied to find the half-period of thorium $\mathrm{E}$. This has been found tentatively to be about $10^{6}$ years.

(c) It has been suggested that the disintegration of thorium $E$ may be accompanied by the loss of a $\beta$ ray, so that the resulting product would be an isotope of bismuth. Evidence has, however, been brought forward which suggests that the latter cannot be a stable end product. Should this 
Group V. $b$ product of thorium be unstable, the method here used for thorium $E$ could be applied to find its disintegration constant, when the bismuth and thorium contents of suitable minerals are known. Information could thus be obtained as to the next succeeding product, which would be a thallium isotope if the bismuth isotope disintegrates with loss of an a ray, or a polonium isotope if the change takes place with loss of a $\beta$ ray.

(d) The evidence of atomic weight determinations of lead extracted from radioactive minerals also points to the stability of radium $G$, and the instability of thorium $\mathrm{E}$. It has been shown that the most suitable mineral for the determination of the atomic weight of radium $G$ is a geologically old, primary, fresh, uranium mineral. Using such a mineral, bröggerite, Hönigschmid and St. Horovitz found the value 206.06 . Should actinium lead have an atomic weight of 210 , the above result for bröggerite would indicate that it is unstable. Experiments to throw light on the stability of actinium lead are suggested in $\$ 13$. If the atomic weight of actinium lead is 206 , we are unable to say whether it is unstable or not. Methods of attacking the question of the end product of actinium have been suggested, and it has been shown how one of these might incidentally throw light on the atomic weight of actinium. For thorium $\mathrm{E}$ it would appear that no very definite conclusions can be drawn from atomic weight determinations, owing to the instability of this element. In the most favourable circumstances, a value of about 207 would be obtained, instead of the theoretical value $208^{\circ} 4$. Determinations of the atomic weights of bismuth and thallium from uranium and thorium minerals, would serve a useful purpose in supplying definite information regarding the end products of thorium and actinium.

(e) Atomic weight estimations can now be used to correct this crude determination of the age of a mineral by means of its present lead and uranium contents. Corrections must be applied both for original lead, which may be considerable (e.g. in some specimens of thorianite from Ceylon), and for a small equilibrium amount of thorium lead. These corrections appear to make very little difference to the timescale as at present constituted. That this is true for the Devonian minerals of Norway we have already seen. The pre-Jatulian minerals of the Moss district of Norway require practically no correction, for bröggerite from that district contains uranium lead in an almost uncontaminated state, as shown by the atomic weight of lead prepared from the 
mineral (206.06 found; 206.2 theoretical value). As more evidence accumulates, the ratios for other geological periods will be similarly tested. At present it would seem that the age of the older intrusive rocks of Ceylon, as deduced from $\mathrm{Pb} / \mathrm{U}$ ratios in thorianite and thorite, is probably too high. These ratios are nearly always greater than 0.2 , giving an age exceeding 1600 million years. Zircon from the same pegmatites, however, gives a ratio of 0.164 (1370 million years), which seems to be more probable, in the light of atomic weight estimations. Zircon is much less likely to contain original lead than thorite or thorianite, and apart from the difficulty of estimating the very small quantities of lead which have accumulated, zircon represents one of the. most valuable minerals for age determinations.

Finally, in addition to our previous acknowledgments to Professors Strutt and Mache, we wish to express our thanks to Professor Stefan Meyer, for his kindly interest and encouragement during the progress of this work.

LXXII. On Ripples. By J. R. Wrutow, M.A., D.Sc., Assistant Lecturer in Mathematics at the University of Sheffield*.

T $\mathrm{N}$ carrying the approximation to the form of a wave to 1 such an extent as is done in my paper on "On Deep Water Waves" (Phil. Mag. Feb. 1914, pp. 385-394), which will here be referred to as "Waves," it is important to make certain that the sense of accuracy thus obtained is not illusory. The present paper therefore takes up the consideration of the corrections which have to be applied. We shall, however, still suppose that the wave (or ripple) is formed under ideal conditions, - that there is no wind, no secondary disturbance of any kind,- that the "ocean" is "deep" (a depth of ten centimetres will be ample for the ripples we shall aetually consider) and of unlimited extent. With this understanding there are three things for which we have to make allowance, namely :-

(1) Surface Tension,

(2) The formation of waves in the air,

(3) Viscosity.

Now the first order approximation to the velocity when (1) and (2) are taken into account is known to be given by

$$
c^{2}=\frac{g \lambda}{2 \pi} \frac{\rho-\rho^{\prime}}{\rho+\rho^{\prime}}+\frac{2 \pi}{\lambda} \frac{\mathrm{T}}{\rho+\rho^{\prime}}
$$

* Communicated by the Author. 